
420 TWO GENERATIONS. Gertrude Costin, Univ. Of So. Calif. sch. of Med., Childrens Hospital of Los Angeles, Dept. of Peds., Los Angeles.

A 6 yr old girl (Pt1) presented with pubic hair, acne and body odor for $1 \mathrm{yr}$. Ht was at the 95 th centile and bone age (BA) was 8 yrs; she had stage II pubic hair, acne and mild clitoromegaly. Serum 17-hydroxyprogesterone (17-OHP), androstenedione, and testosterone (T) were 218,46 and $40 \mathrm{ng} / \mathrm{dl} ; \mathrm{LH}, \mathrm{FSH}$ and E2 were prepubertal. Her sister (Pt2) was asymptomatic at $2 \frac{1}{4}$ rs; at $3 \frac{1}{4}$ yrs her ht had increased from the 75 th to the 90 th centile and her BA was $4 \frac{1}{y r s}$. She had occasional acne and body odor. Their 9 yr old brother (Pt3) was at the 50th centile for ht with a BA of 9 yrs and no signs of virilization. The mother (Pt4) was $162 \mathrm{~cm}$ tall, obese and hirsute; she had clitoromegaly and irregular menses. The father (Pt5) was $170 \mathrm{~cm}$ tall and apparently normal. Basal (B) and Cortrosyn ${ }^{\circledR}$ stimulated $(S)$ serum adrenal steroids are listed below.

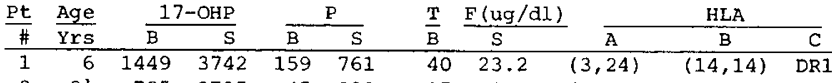
$\begin{array}{rrrrrrrrrrr}1 & 6 & 1449 & 3742 & 159 & 761 & 40 & 23.2 & (3,24) & (14,14) & \text { DR1 } \\ 2 & 21 & 785 & 2735 & 45 & 232 & 15 & 22.9 & (3,33) & (14,14) & \text { DR1 } \\ 3 & 9 & 611 & 4500 & <10 & 283 & 38 & 14.2 & (24,28) & (14,14) & \text { DR1 }\end{array}$ $\begin{array}{rrrrrrrrrrr}3 & 9 & 611 & 4500 & <10 & 283 & 38 & 14.2 & (24,28) & (14,14) & \text { DR1 } \\ 4 & 39 & 199 & 3224 & <10 & 84 & 67 & 18.6 & (3,28) & (14,14) & \text { DR1 }\end{array}$

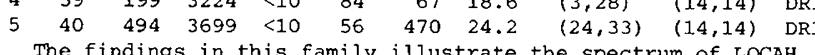
The findings in this family illustrate the spectrum of LOCAH ranging from no symptoms (Pts 3,5 ), to rapid growth (Pts1,2), premature pubarche and clitoromegaly (Pt1), and post pubertal hirsutism and oligomenorrhea (Pt4). There appears to be no correlation between the biochemical abnormalities and the clinical manifesta-
tions of the disease.
HYPOPITUITARISM AND PRECOCIOUS PUBERTY (PP). G. Costin

421 and F. Kaufman. Univ. of So. Cal. Sch. of Med., Dept. Three girls and one boy with Hosp. Of Los Angeles, Los Angeles. tosis $(\$ 2,3)$ and to cranial radiation for a craniopharyngioma (\#1) and a thalamic tumor (\#4) developed PP. Signs of sexual precocity were noted prior to treatment with somatotropin (HGH) in $3 \mathrm{pa-}$ tients, and during the course of therapy in one. Clinical and laboratory data are indicated below.

\begin{tabular}{|c|c|c|c|c|c|c|c|c|c|}
\hline sex & $\underline{\mathrm{CA}}$ & $\frac{\mathrm{HA}}{(\overline{Y r S})}$ & BA & $\frac{\text { Tanner }}{\text { (stage) }}$ & $\frac{\text { Peak GH }}{(\mathrm{ng} / \mathrm{ml})}$ & $\frac{\operatorname{SmC}}{(\mathrm{U} / \mathrm{m} \mathrm{I})}$ & $\frac{\mathrm{LH}}{(\mathrm{m} I \mathrm{IU}}$ & $\frac{\text { FSH }}{\mathrm{ml})}$ & $\frac{\mathrm{E} 2 / \mathrm{T}}{(\mathrm{ng} / \mathrm{d} \mathrm{l}}$ \\
\hline $1 / \mathrm{F}$ & 7 & $6 \frac{1}{2}$ & $5 \frac{1}{2}$ & II & 3.7 & 0.2 & 6.1 & 6.2 & 4.0 \\
\hline $2 / F$ & $7 \frac{1}{2}$ & 6 & $4 \frac{1}{2}$ & II & 5.0 & 0.9 & 2.0 & 4.4 & 3.0 \\
\hline $3 / F$ & 8 & $5 \frac{1}{2}$ & 7 & $I I-I I I$ & 4.3 & 0.5 & 8.0 & ND & 5.0 \\
\hline $4 / M$ & $8 \frac{1}{2}$ & $4 \frac{1}{2}$ & $7 \frac{1}{2}$ & $I I-I I I$ & 3.5 & 0.9 & 5.2 & 12 & 100 \\
\hline
\end{tabular}
While in patient \#2 there was a normal growth velocity associated with puberty, in patient \#3 the growth spurt was subnormal; in both
patients menses started at $11-11 \frac{1}{2}$ yrs. Five yrs after the onset of $\mathrm{PP}$ the $\mathrm{CA} / \mathrm{HA} / \mathrm{BA}$ ratios in patients \#2 and 3 were $12 \frac{1}{2} / 11 \frac{1}{2} / 14$ and $13 \frac{1}{2} / 10 \frac{1}{2} / 15$, respectively. In the other 2 patients, the CA/HA/BA ratios $1 \frac{1}{2}$ yrs after onset of PP were $8 \frac{1}{2} / 7 \frac{1}{2} / 7 \frac{1}{2}(\# 1)$ and $10 / 5 \frac{1}{2} / 10$ (\#4).

These findings indicate that 1) sexual precocity does occur in the presence of hypopituitarism, 2) there is a rapid skeletal maturation before clinical signs of $\mathrm{PP}$ are apparent, and 3 ) the pubertal growth spurt even if adequate does not result in a normal adult height if there is an abnormal HA/BA ratio at the onset of PP. We submit that in these patients for achievement of an average height PP must be curtailed by pharmacologic means until the HA/BA. ratio is normalized by treatment with $\mathrm{HGH}$.

\section{CLONING OF CDNA ENCODING BOVINE 21-HYDROXYTASE.} † 422 Bon-Chu Chung, Karla J. Matteson, John E. Morin, \&
University of California, San Francisco, CA
Over $90 \%$ of cases of congenital adrenal hyperplasia are due

Over $90 \%$ of cases of congenital adrenal hyperplasia are due
to disordered 2l-hydroxylation, which converts progesterone and to disordered 21-hydroxylation, which converts progesterone and
17-hydroxyprogestone (17-OHP) to DOC and ll-deoxycortisol. 21-hydroxylase is a single 49000 dalton microsomal cytochrome $\mathrm{P} 450$, termed P450 which represents $<0.18$ of adrenocortical protein. We prepfited polyadenylated messenger RNA (mRNA) fram demedulated bovine adrenals and used this mRNA as template for the synthesis of double stranded (DS) complementary DNA (CDNA). The $3^{\prime}$ ends of the DScDNA were extended with deoxycytosine using The $3^{\prime}$ ends of the DSCDNA were extended with deoxycytosine using
terminal deoxymucleotidyl transferase; this "tailed" DScDNA was terminal deoxynucleotidyl transferase; this "tailed" DSCDNA was
inserted into the Pst I site of pBR322 similarly tailed with
deoxyguanosine. Transformation of E. coli 294 yielded $>60,000$ clones. Based on a partial porcine amino acid sequence, we used the manual phosphoramidite method to synthesize a family of 32 15-base oligonucleotides and used these to prime the synthesis of a specific CDNA probe. Clones hybridizing to the 15merprimed CDNA were then probed with a different family of 64 primed CDNA were then probed with a different family of 64 portion of the amino acid sequence. Of 10,000 clones containing CDNA inserts longer than 800 bases, 5 hybridize efficiently with both probes, indicating they carry bovine P450 CDNA sequences. These DNA clones will permit the determination of the structure of bovine $\mathrm{P}^{450} \mathrm{C}_{\mathrm{C} 21}$ as well as human $\mathrm{P}^{2} 50_{\mathrm{C} 21}$ and its
THE EFFECT OF GLUCOSE (G) AND ESSENTIAL AMINo ACIDS

423 (EAA) ON INSULIN (I) BIOSYNTHESIS AND RELEASE IN HU. Mi MAN FETAL PANCREAS CULTURES (HFPC). Agnes A. Cser, R.D. G. Milner, Dept.Ped., Univ. Sheffield, England. (Spon. by T. Heim). feration and may provide a suitable source for transplantation in treating diabetes mellitus. In order to characterize its insulin producing capacity, 8 human fetal pancreases of 13-20 wk. gest. were studied in organ culture for 7 days. DNA and insulin content and release into the culture-medium from day 3 to 7 were measured. Two types of medium both supplemented with $20 \%$ (W/V) heated fetal calf serum were used: 1) Eagle's minimum essential medium (MEM) was supplemented with 6 times the basal concentration of EAA containing 5 (7EAA1G) or 16.5 (7EAA3G) mmol/1 glucose and 2) "RPMI 1640 medium" contained 11.6 (R) or 23.2 (RG) mmol/l glucose. Glucose enrichment increased tissue insulin content ( $\mu \mathrm{U}$ / $\mu \mathrm{g}$ DNA) by 44 to $263 \%$ in 7 EAA $(20.5 \pm 1.5$ in $1 \mathrm{G}$ vs $38.9 \pm 2.6$ in $3 G ; p<0.01$ ) and by 34 to $276 \%$ in RPMI ( $16.9 \pm 1.5$ in $R$ vs $36.2 \pm 2.9$ in $R G ; p<0.01)$. High EAA concentration itself favoured tissue insulin synthesis (7EAAlG larger than $R ; 0 \times 0.001$ and $R G 31.1 \pm 5.7$ vs $\mathrm{R} 12.1 \pm 2.6 \mu \mathrm{U} / \mu \mathrm{g} \mathrm{DNA} ; \mathrm{p}=0.001$ ). The insulin specific activity ( $\mu \mathrm{U}$ I/ $\mu \mathrm{g}$ DNA) of FPT increased with gest. age being 0.24 at wk. 13 and 1.62 at wk. 20 in the fresh tissue and after 7 days of culture 25.2 at wk. 13 and 61.3 at wk. 20. Results indicate: 1) both insulin synthesis and release of FPT and HFPC increased in response to glucose and essential amino acids and 2) the combination of high glucose and high essential amino acids containing medium can potentiate the fetal pancreatic tissue capacicy for insulin synthesis in a transplant.

424 GROWTH HORMONE RELEASE FOLLOWING ADMINISTRATION OF GROWTH HORMONE RELEASING FACTOR TO GROWTH HORMONE Kenneth Lee Jones, UCSD School of Medicine, Dept. of Pediatrics, La Jolla, California.

We have studied 4 males with idiopathic growth hormone (hGH) deficiency and 8 normal adult males comparing their responses to a $100 \mu \mathrm{g}$ bolus infusion of the 44 amino acid synthetic growth hormone releasing factor (GRF-44). Responses were compared for changes in hGH, prolactin (PRL), insul in (I), glucagon (G) and g1ucose (Glu) concentration over a 2-hour period after injection of GRF-44. hGH deficiency was initially documented using standard testing procedures. No patient had received hGH replacement for at least one month prior to testing.

The hGH deficient patients had a significant $(p<0.05)$ GRFinduced increase in hGH concentration from a baseline of $2.7 \pm 0.7$ $\mathrm{ng} / \mathrm{ml}(\mathrm{M} \pm \mathrm{SEM})$ to a peak of $10.3 \pm 3.2 \mathrm{ng} / \mathrm{ml}$. The normal males showed a much greater $(p<0.005)$ change in hGH levels with a peak response of $46.0 \pm 5.8 \mathrm{ng} / \mathrm{ml}$ from a baseline of $2.98 \pm 0.1 \mathrm{ng} / \mathrm{ml}$.

There were no changes in PRL, Glu, I or $G$ in either group.

We have demonstrated that patients wi th subnormal hGH responses to traditional stimuli can generate $h G H$ levels in the normal range (>7 ng/m1) following GRF stimulation. The mean increase of the hat deficient group, however, was only $2.2 \%$ of the mean increase of the group of normal male controls. This confirms that patients with idiopathic hri! deficiency may have holl rolease, though it is subnormal, following single bolus GRF-44 testing.

425 sity of Toronto, Hosp. for Sick Children, Toronto, Canada 69 children were detected by a low thyroxine (T4) and/o elevated thyrotropin (TSH) on neonatal screening to have congenital hypothyroidism $(\mathrm{CH})$. Of these, 55 are 3 years of age or older. Thyroid scanning at diagnosis showed $16 / 55$ were athyrotic (A), 21/55 had goiters (G) and 18 with ectopic (E) glands. E were excluded because of the anatomic abnormality. 22 of the remaining 37 showed a secondary rise of TSH to $>10$ mU/L confirming the diagnosis during the first 3 years. In 15 with continuous TSH suppression, thyroxine was discontinued at age 3 years or more. In the first 6 , TSH was measured at 6 weeks: in $5 / 6$ it was $>60$, in 1 with $G-C H$, TSH was 7 at 6 weeks and 15 at 8 weeks. Symptoms of hypothyroidism occurred in $4 / 6$. TSH was then measured at 3 weeks and was $>60$ in the remaining 10. When the $\mathrm{rSH}$ was elevated, T4 was $40 \pm 39 \mathrm{nmol} / \mathrm{L}(\overline{\mathrm{X}} \pm \mathrm{SD})$. In all patients with $\mathrm{A}-\mathrm{CH}$ or $\mathrm{G}-\mathrm{CH}$, the diagnosis was confirmed either by a secondary rise of TSH while on treatment or by a $\mathrm{TSH}$ rise at 3-6 weeks after discontinuing therapy. In this group, thyroid screening appears to be $100 \%$ specific. Hypothalamic-pituitary responsiveness and hypothyroid symptoms return very rapidly after stopping L-T4 therapy. We recommend $\mathrm{CH}>3$ years in whom confirmation of desirable. 